\title{
O circuito quatro desafios - Atividade lúdica apoiada pelo Pensamento Computacional
}

\author{
Caroline dos Santos Gonçalves ${ }^{1}$, Lídia Raquel Rocha Cunha ${ }^{1}$, Graziela Ferreira \\ Guarda $^{1}$, Ione Ferrarini Goulart ${ }^{2}$ \\ ${ }^{1}$ Departamento de Computação - Universidade Católica de Brasília (UCB) \\ Campus I - QS 07 - Lote 01 - EPCT - Águas Claras - Brasília - DF CEP: 71966-700. \\ ${ }^{2}$ Área de Informação e Comunicação - Instituto Federal de Brasília (IFB) \\ Campus Brasília - SGAN 610 Módulo D, E, F e G - CEP: 70830-450. \\ carolsantosg95@gmail.com, lidiaraquelrocha@hotmail.com, \\ grazielafguarda@gmail.com, ionefg@gmail.com
}

\begin{abstract}
With the objective of propagating the teaching of logical and mathematical reasoning together with the logic of programming, the project Logicamente was created, which uses as teaching tools digital and ludic games in an unplugged environment, performing practices that lead to differentiated results in the learning process in this sense was carried out the activity "The 4 circuits". The circuit explored four areas with different games that work through the lucidity contents that range from the domain of arithmetic operations to the application of algorithms in the everyday, with the purpose of developing, in parallel, Computational Thinking skills. In this sense, it was sought to stimulate the creativity and the development of different competences.
\end{abstract}

Resumo. Com o objetivo de propagar o ensino do raciocínio lógico e matemático aliado à lógica de programação se criou o projeto Logicamente, que utiliza como ferramentas de ensino jogos digitais e lúdicos em ambiente desplugado realizando práticas que conduz a resultados diferenciados no processo de aprendizagem, neste sentido foi realizada a atividade "Os 4 circuitos". O circuito explorou quatro áreas com diferentes jogos que trabalham através da ludicidade conteúdos que envolvem desde o domínio de operações aritméticas até a aplicação de algoritmos no cotidiano, com o propósito de desenvolver, paralelamente, habilidades do Pensamento Computacional. Neste sentido, se buscou estimular a criatividade e o desenvolvimento de diferentes competências.

\section{Introdução}

O presente relato de experiência se refere a uma atividade lúdica proposta por um projeto de pesquisa intitulado Logicamente cujo enfoque é desenvolver competências e habilidades advindas do Pensamento Computacional (PC) com estudantes da Educação Básica. Neste sentido, foi desenvolvida uma atividade denominada de "Os 4 circuitos" cujo enfoque foi trabalhar o raciocínio lógico, matemático e computacional alinhado com os objetivos do projeto.

O PC pode ser compreendido com um instrumento interventor que auxilia na resolução de problemas, baseado nos conceitos fundamentais da ciência da computação 
(Wing, 2006) e expor essas ferramentas mentais a estudantes da Educação Básica vai em consonância com as diretrizes da Sociedade Brasileira de Computação (SBC) que considera fundamental e estratégico para o Brasil que conteúdos de computação sejam ministrados na Educação Básica (SBC, 2017).

Em complemento, a atividade também explora o reforço educacional da área de matemática que se faz tão necessário tendo em vista o baixo nível de proficiência apresentado pelos estudantes (Educação Básica - INEP, 2018). Neste sentido, o presente estudo visa contribuir para a inclusão de um processo de ensino-aprendizagem no qual o desenvolvimento do raciocínio lógico, matemático e computacional são estimulados através de práticas que abordam desafios em consonância com as habilidades do PC.

Este artigo está dividido da seguinte maneira: a seguir, na Seção 2, é apresentada uma explicação sobre o circuito e a metodologia utilizada, bem como, sua organização. Os resultados parciais são descritos na Seção 3. Por fim, os resultados desta experiência serão destacados na Seção 4, de forma a concluir o propósito do circuito diante dos resultados já obtidos.

\section{Proposta e Metodologia}

A ideia do circuito do raciocínio lógico matemático surgiu oriundo do conjunto de atividades abordadas pelo projeto de pesquisa Logicamente amparado pela ludicidade como ferramenta do desenvolvimento do aprendizado. O público-alvo do desafio foram três turmas do $5^{\circ}$ e $6^{\circ}$ ano do ensino fundamental de uma escola particular do Distrito Federal, com um total de 12 equipes compostas por 7 a 3 integrantes cada - este número variou em função da quantidade de estudantes de cada turma.

Em relação a organização das áreas do circuito, a sala foi dividida em quatro áreas, cada uma representada por uma cor e um número com o propósito de deixar o ambiente mais organizado, manter a privacidade dos grupos, bem como, não prejudicar a concentração dos estudantes conforme ilustrado na Figura 1.

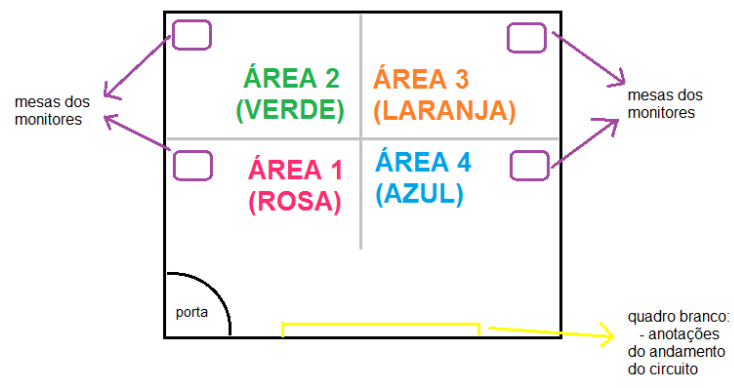

Figura 1. Organização do Ambiente

Essa divisão favoreceu a dinâmica do circuito. Cada área dispôs de uma atividade diferente e foi acompanhada por um monitor que exerceu a função de auxiliar os grupos para fins de esclarecimento de dúvidas. Paralelamente, os monitores ficaram responsáveis, ainda, por avaliar o desempenho dos estudantes e o desenvolvimento da atividade, observando sua efetividade e quais habilidades e competências do PC estavam sendo trabalhadas.

Quanto a dinâmica utilizada, o tempo total destinado a execução da atividade foi 100 minutos. Primeiramente, foi explicado o funcionamento do circuito aos estudantes. 
VII Congresso Brasileiro de Informática na Educação (CBIE 2018)

Anais dos Workshops do VII Congresso Brasileiro de Informática na Educação (WCBIE 2018)

Em seguida, os mesmos foram divididos em quatro grupos que, inicialmente, ocuparam uma área determinada. Os grupos foram divididos pelos monitores com o intuito de desfazer equipes viciadas, visando uma maior autonomia e o trabalho em diferentes equipes, de maneira a tirá-los da zona de conforto de continuarem trabalhando somente com os mesmos colegas. Com os grupos já formados foi decidido, por meio de sorteio, a área em que cada grupo iria se posicionar.

O critério para divisão dos grupos se deu também considerando o desenvolvimento dos estudantes no projeto, de modo que, os estudantes que possuíam facilidade em desenvolver as atividades propostas, foram agrupados com os que possuíam dificuldade em realizar as atividades e para cada grupo foi definido um líder, a função do líder era receber as medalhas (que teria uma pontuação).

Deste modo, se objetivou trabalhar as relações interpessoais e por fim, auxiliar o processo de resolução do problema equilibrando o potencial de cada equipe. Após distribuído cada grupo nas áreas, foi dado o início a atividade lúdica de modo que, cada equipe tinha 20 minutos para resolver cada parte do circuito. Ao final dos 20 minutos, independente da conclusão do desafio daquela área, as equipes avançavam para a próxima área trocando de atividade no sentido horário. A Tabela 1 abaixo demonstra como foram realizadas as etapas do circuito, e seus respectivos tempos máximos.

Tabela 1. Esquema do circuito

\begin{tabular}{|l|l|l|}
\hline Ação: & \multicolumn{1}{|c|}{ Composição do circuito: } & Duração: \\
\hline 1 & Explicação de regras e realização do sorteio. & 10 minutos \\
\hline 2 & Primeiro ciclo & 20 minutos \\
\hline 3 & Segundo ciclo & 20 minutos \\
\hline 4 & Terceiro ciclo & 20 minutos \\
\hline 5 & Quarto ciclo & 20 minutos \\
\hline 6 & Contagem dos pontos e premiação da equipe campeã & 10 minutos \\
\hline
\end{tabular}

Ao concluir o desafio de cada área, o líder da equipe ganhava uma medalha que valia 400 pontos, de modo que, cada equipe poderia atingir a pontuação máxima de 1600 pontos. Como critério de penalização, alguns objetos foram definidos: equipes que produzissem barulho excessivo perdia 50 pontos e equipes que copiassem a solução de outra equipe perdia 100 pontos. Nos casos de empate, seria realizada uma prova surpresa.

Em relação a atividade em si, os desafios do circuito foram dividos em quatro áreas: Desafio do Tangram, Desafio do Resta 1, Desafio da Expressão Numérica e Desafio dos Fazendeiros conforme descritos abaixo:

Desafio do Tangram: Área 1 (rosa). Inspirado nos antigos quebra cabeças chineses é um jogo composto por sete peças geométricas, são elas: dois triângulos isósceles grandes, dois triângulos isósceles pequenos, um triângulo isóscele médio, um quadrado, um paralelogramo. Esse quebra cabeça pode formar várias figuras e formas que podem ser de animais, pessoas ou objetos. Desenvolvendo a abstração, reconhecimento e manipulação de figuras geométricas.

A temática do Tangram foi em abordado em duas aulas teóricas anteriormente. Na primeira foi apresentada aos estudantes a definição de figura geométrica e de sólidos. 
VII Congresso Brasileiro de Informática na Educação (CBIE 2018)

Anais dos Workshops do VII Congresso Brasileiro de Informática na Educação (WCBIE 2018)

Posteriormente, foram entregues sólidos geométricos aos estudantes, e com isso eles tiveram a vivência do conteúdo junto com o reconhecimento das figuras na vida real tendo a condição de identificar e classificar as figuras encontradas na sala.

Finalizando a aula, os estudantes produziram seus próprios quebra-cabeças e ficaram com a atividade de desenvolver uma figura sem consultar a Internet. Na segunda aula foi feita uma recapitulação da primeira aula, logo após, foi disponibilizado para os estudantes uma versão online do Tangram 32 (Tangram, 2017). Esse foi o jogo utilizado como fundamento para o desafio da área 1.

Dentro do circuito, os grupos receberam 15 silhuetas (com exceção da turma 3 que teve somente 12 silhuetas) para em 20 minutos montar corretamente. A Figura 2 abaixo ilustra a atividade de um dos grupos. Observação: $O$ projeto dispõe de termo de autorização do uso das imagens utilizadas.

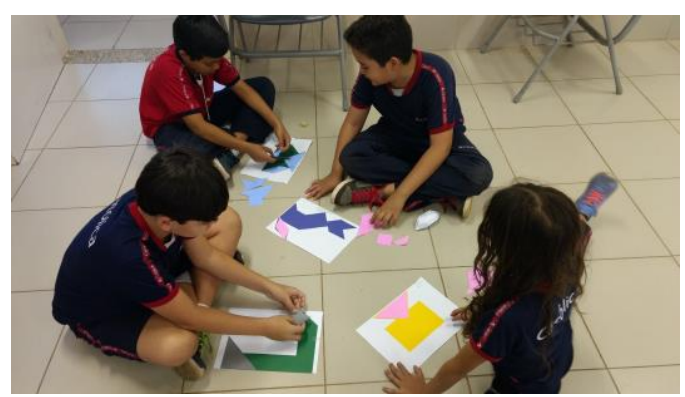

Figura 2. Área 1 - Tangram

Desafio do Resta 1: Área 2 (verde). O Resta 1 tradicional (ou Solitaire) é um jogo inglês formado por um tabuleiro com trinta e três casas, dispostas em forma de cruz onde 32 casas são ocupadas pelas peças do jogo, deixando a casa central vazia. $\mathrm{O}$ objetivo do jogo é retirar as peças, com um movimento semelhante ao jogo de damas, de forma a sobrar somente uma peça, justamente na casa do centro do tabuleiro.

Preliminarmente ao circuito, em sala de aula, foi apresentado a história, explicado o funcionamento e objetivos do jogo, bem como, apresentado um jogo virtual que demonstrava várias opções de formação do jogo, com diferentes graus de dificuldade. Assim como qualquer jogo de tabuleiro é importante que, ao realizar uma jogada, seja feita uma previsão das seguintes. Com o resta 1, buscou-se desenvolver não somente essa abstração e visão de jogo, como também o reconhecimento de padrões em alguns lances que se repetiam e apresentavam os mesmos resultados. A Figura 3 demonstra a atividade em execução por um dos grupos.

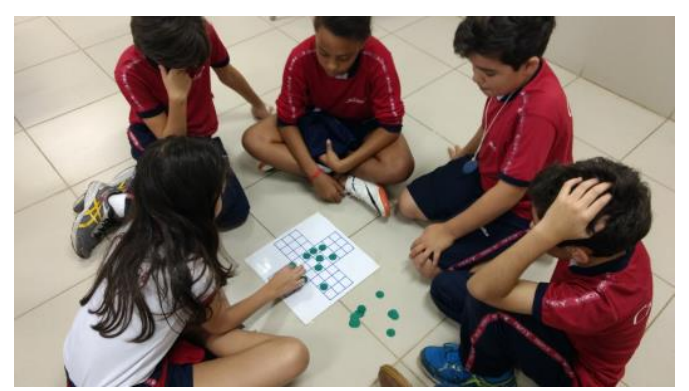

Figura 3. Área 2 - Resta Um 
VII Congresso Brasileiro de Informática na Educação (CBIE 2018)

Anais dos Workshops do VII Congresso Brasileiro de Informática na Educação (WCBIE 2018)

Desafio da Expressão Numérica: Área 3 (laranja). Com o objetivo desenvolver a habilidade solucionar um problema através da decomposição, ou seja, pegar um problema complexo e dividi-lo em partes menores, foi aplicado no circuito a Expressão Numérica. Na aula preliminar ao lúdico, destinada a expressões numéricas foram reforçadas as regras para se resolver uma equação, dando destaque a hierarquia das operações aritméticas (potências e raízes; divisão e multiplicação; adição e subtração), a hierarquia de símbolos (parênteses; colchetes; chaves), bem como, os sentidos de resolução (esquerda para a direita), em seguida foi aplicado um jogo virtual que trabalhava o assunto para fins de exercitação.

No circuito da matemática, além da decomposição do problema, os estudantes deveriam trabalhar em equipe para resolver a expressão no tempo determinado e consequentemente, lidar com mais de uma tarefa ao mesmo tempo, já que ao dividir tarefas, é preciso pensar na outra parte. A partir de dados previamente conhecidos, os grupos tiveram que resolver um problema aritmético com a utilização da simplificação, regras e decomposição. Segue abaixo, na Figura 4 uma imagem que ilustra a Equação Numérica sendo executada por um dos grupos, bem como, na Figura 5, a expressão utilizada.

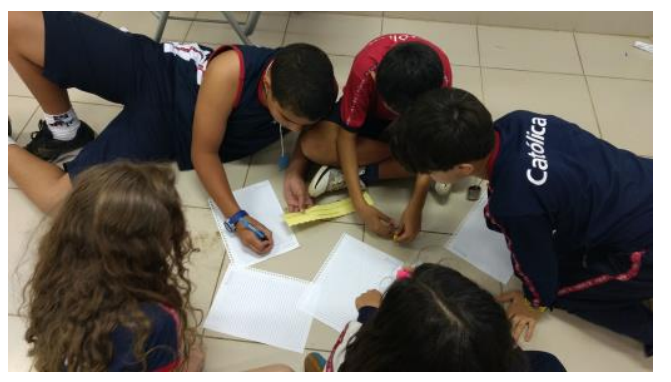

Figura 4. Área 3 - Equação Numérica

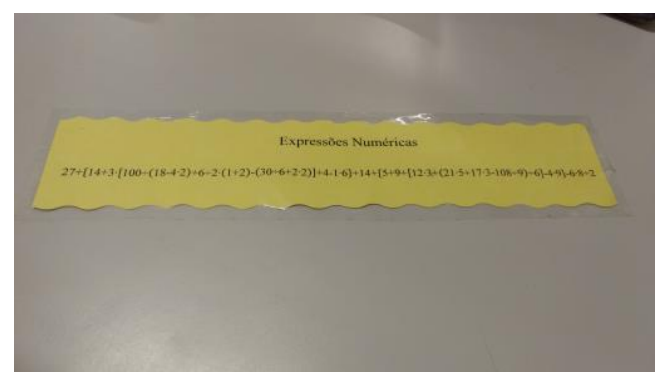

Figura 5. Equação Numérica

Desafio do Desafio do fazendeiro: Área 4 (Azul). Por fim, foi destinada à área 4 um desafio lógico, chamado de Desafio do Fazendeiro. Ao chegar na área, a monitora apresentava o seguinte problema: "Um fazendeiro quer levar o leão, o burro e o feno para o outro lado do rio. Porém, ele não pode levar o leão junto com o burro, pois este o comeria. Nem o burro com o feno. ". Solucionado o problema, era entregue ao grupo um papel que os estudantes deveriam escrever um algoritmo que representasse a solução do problema. A monitora estava instruída a fazer a verificação do algoritmo, ou seja, em caso de erro na lógica, nas regras e na escrita. $\mathrm{O}$ algoritmo deveria ser entregue ao grupo para que fosse realizada uma outra tentativa, a Figura 6 abaixo demonstra o desafio da área.

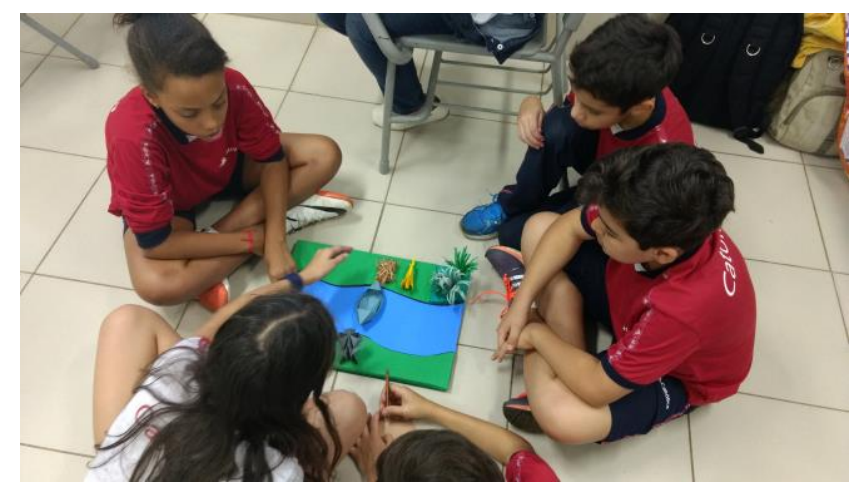


VII Congresso Brasileiro de Informática na Educação (CBIE 2018)

Anais dos Workshops do VII Congresso Brasileiro de Informática na Educação (WCBIE 2018)

\section{Figura 6. Área 4 - Desafio do Fazendeiro}

Por fim, segue abaixo na Tabela 2 um quadro que reúne todas as características e informações do circuito, materiais utilizados e as respectivas habilidades do pensamento computacional trabalhados em casa área.

Tabela 2. Descrição dos desafios das áreas

\begin{tabular}{|l|l|l|l|l|}
\hline Desafio: & Área: & O que consiste: & Material Utilizado: & Habilidades do PC: \\
\hline Tangram & Área 1 & $\begin{array}{l}\text { Montar corretamente a } \\
\text { figura de 15 silhuetas } \\
\text { utilizando o quebra } \\
\text { cabeça. }\end{array}$ & $\begin{array}{l}\text { Folhas de papel com a sombra } \\
\text { da figuras e peças de papel do } \\
\text { Tangram. }\end{array}$ & $\begin{array}{l}\text { Abstração; Análise de } \\
\text { Dados; Construção de } \\
\text { Algoritmo. }\end{array}$ \\
\hline Resta 1 & Área 2 & $\begin{array}{l}\text { Um jogo tradicional de } \\
\text { tabuleiro, cujo o } \\
\text { objetivo é eliminar as } \\
\text { peças do jogo de forma } \\
\text { que só reste uma. }\end{array}$ & $\begin{array}{l}\text { Folhas de papel com a } \\
\text { marcação do tabuleiro e } \\
\text { círculos de papel cartão para } \\
\text { representar as peças. }\end{array}$ & $\begin{array}{l}\text { Abstração; Construção } \\
\text { de } \\
\text { Paralelismo }\end{array}$ \\
\hline $\begin{array}{l}\text { Expressão } \\
\text { Numérica }\end{array}$ & Área 3 & $\begin{array}{l}\text { Resolução de uma } \\
\text { expressão numérica. }\end{array}$ & $\begin{array}{l}\text { Folhas de papel A4, lápis e } \\
\text { borracha. }\end{array}$ & $\begin{array}{l}\text { Decomposição; } \\
\text { Abstração; Paralelismo. }\end{array}$ \\
\hline $\begin{array}{l}\text { Desafio do } \\
\text { Fazendeiro }\end{array}$ & Área 4 & $\begin{array}{l}\text { Um desafio lógico. } \\
\text { Uma maquete do cenário } \\
\text { (margens do rio), cartões para } \\
\text { escrever a solução e origamis } \\
\text { de leão, burro e barco, além da } \\
\text { representação feno. }\end{array}$ & $\begin{array}{l}\text { Coleta de dados; Análise } \\
\text { Algoritmo e Paralelismo. }\end{array}$ \\
\hline
\end{tabular}

De acordo com os dados da Tabela 2, o lúdico "4 circuitos" trabalhou 6 das 9 habilidades do PC de acordo com (CSTA, 2011) que são: Abstração: capacidade de filtrar informações essenciais e descartar as informações desnecessárias em um determinado contexto; Decomposição: quebrar um problema grande em partes menores; Coleta de Dados: encontrar dados necessários para resolver um problema; Análise de Dados: atribuir sentido a dados, encontrando padrões e conclusões; Construção de Algoritmo: sequências lógicas para alcançar um objetivo; e Paralelização: identificar atividades que podem ser executadas em paralelo. Esses conceitos também foram explanados e discutidos com as turmas preliminarmente a execução da atividade.

\section{Resultados e Discussões}

A atividade abordada foi desenvolvida para ser aplicada de maneira uniforme nas três turmas de forma a preservar à confiabilidade dos dados. A princípio, a dinâmica do jogo foi de fácil entendimento para os estudantes, por consequência, ficaram bastante animados para o início das atividades.

Em relação a Área 1 - Tangram, todos os grupos das três turmas foram orientados a dividir as tarefas pois trabalhando em grupo seria mais fácil e rápido concluir a atividade. Em relação a turma três, como a média de estudantes por grupo era menor, houve um consenso entre os monitores de reduzir o número de silhuetas de 12 para 9, de modo a manter o equilíbrio de proporcionalidade entre o número de silhuetas para o número de estudantes. No entanto, na turma 2, que também tinha uma menor quantidade de integrantes por grupo, não houve essa percepção por parte dos monitores, portanto, tal requisito não foi respeitado, interferindo diretamente nos resultados. 
VII Congresso Brasileiro de Informática na Educação (CBIE 2018)

Anais dos Workshops do VII Congresso Brasileiro de Informática na Educação (WCBIE 2018)

Nesta atividade, se observou que alguns grupos se desenvolveram melhor devido à presença de um integrante que tinha maior facilidade com o raciocínio exigido pela atividade, como a paralelismo e a análise de dados (habilidades do PC) com o intuito de encontrar a melhor forma de montar as silhuetas com as peças do jogo. Como consequência, os estudantes de destaque se tornaram referência para os outros integrantes, de tal modo que, eles eram sempre requisitados para auxiliar os demais. A Tabela 3 que demonstra os resultados dos grupos por turma.

Tabela 3. Resultados Área 1

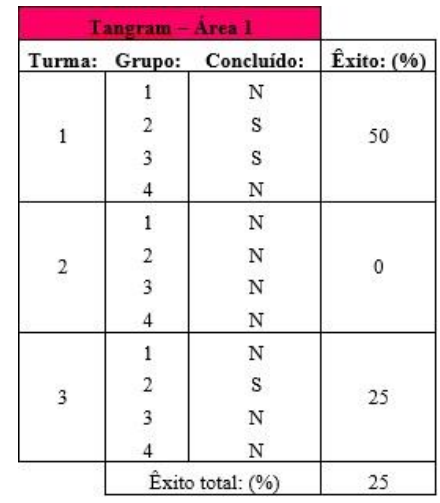

De acordo com o exposto na Tabela 3, apenas 3 grupos concluíram a atividade por completo, essa situação ocorreu, pois, o tempo destinado a essa área do circuito foi considerado insuficiente.

Em relação a Área 2 - Resta Um, foi perceptível a maior dificuldade dos estudantes para com esse instrumento, em função do mesmo requerer uma alta habilidade na construção de algoritmos necessitando também de planejamento nas jogadas. Do mesmo modo, foi necessário à coleta e análise correta dos dados, junto à abstração, eliminando informações desnecessárias para a conclusão. Essas considerações foram feitas pelos próprios estudantes. A Tabela 4 demonstra os resultados dos grupos por turma.

Tabela 4. Resultados Área 2

\begin{tabular}{|c|c|c|c|}
\hline \multicolumn{3}{|c|}{ Resta 1 - Área 2} & \\
\hline Turma: & Grupo: & Concluído: & Êxito: (\%) \\
\hline \multirow{4}{*}{1} & 1 & s & \multirow{4}{*}{50} \\
\hline & 2 & $\mathrm{~s}$ & \\
\hline & 3 & $\mathrm{~N}$ & \\
\hline & 4 & $\mathrm{~N}$ & \\
\hline \multirow{4}{*}{2} & 1 & $\mathrm{~S}$ & \multirow{4}{*}{100} \\
\hline & 2 & $\mathrm{~s}$ & \\
\hline & 3 & s & \\
\hline & 4 & $\mathrm{~s}$ & \\
\hline \multirow{4}{*}{3} & 1 & $\mathrm{~N}$ & \multirow{4}{*}{0} \\
\hline & 2 & $\mathrm{~N}$ & \\
\hline & 3 & $\mathrm{~N}$ & \\
\hline & 4 & $\mathrm{~N}$ & \\
\hline & \multicolumn{2}{|c|}{ Êxito total: (\%) } & 50 \\
\hline
\end{tabular}

Diante do exposto na Tabela 4, se percebe que em contraste as outras turmas, a turma 3 teve o pior desempenho para esse e outros instrumentos das outras áreas. Essa situação é decorrente da falta de preparo anterior. Nas duas primeiras turmas, foram utilizados jogos virtuais preliminarmente, em laboratório, buscando familiaridade e 
VII Congresso Brasileiro de Informática na Educação (CBIE 2018)

Anais dos Workshops do VII Congresso Brasileiro de Informática na Educação (WCBIE 2018)

consequentemente, um maior desempenho dos estudantes para com os jogos. Na turma 3 essa ação não ocorreu em função da disparidade entre os cronogramas de execução do projeto Logicamente.

Em relação a Área 3 - Expressão Numérica, visto que a expressão utilizada foi demasiadamente grande em comparação àquelas que foram trabalhadas em sala de aula, a complexidade em relação ao tamanho da expressão foi proposital, de modo a incitar o trabalho em equipe e a distribuição de tarefas. Neste desafio foi de grande importância a colaboração do monitor, pois o mesmo teve função indispensável na mediação dos grupos. De modo geral, as equipes não desenvolveram a percepção de divisão de tarefas, que poderiam decompor a expressão em pequenas partes e depois juntar para chegar ao resultado final. A Tabela 5 abaixo demonstra os resultados dos grupos por turma.

Tabela 5. Resultados Área 3

\begin{tabular}{|c|c|c|c|}
\hline \multicolumn{3}{|c|}{ Expressão numérica - Área 3} & \multirow[b]{2}{*}{$\begin{array}{c}\text { Êxito: } \\
(\%)\end{array}$} \\
\hline Turma: & Grupo: & Concluído: & \\
\hline \multirow{4}{*}{1} & 1 & $\mathrm{~s}$ & \multirow{4}{*}{50} \\
\hline & 2 & $\mathrm{~N}$ & \\
\hline & 3 & $\mathrm{~N}$ & \\
\hline & 4 & $\mathrm{~s}$ & \\
\hline \multirow{4}{*}{2} & 1 & $\mathrm{~S}$ & \multirow{4}{*}{100} \\
\hline & 2 & $\mathrm{~s}$ & \\
\hline & 3 & $\mathrm{~s}$ & \\
\hline & 4 & $\mathrm{~S}$ & \\
\hline \multirow{4}{*}{3} & 1 & $\mathrm{~N}$ & \multirow{4}{*}{0} \\
\hline & 2 & $\mathrm{~N}$ & \\
\hline & 3 & $\mathrm{~N}$ & \\
\hline & 4 & $\mathrm{~N}$ & \\
\hline & \multicolumn{2}{|r|}{ total: (\%) } & 50 \\
\hline
\end{tabular}

De acordo com os dados da Tabela 5, alguns dos grupos não conseguiram finalizar a atividade em função de dificuldades pontuais com habilidades matemáticas e, também, em alguns casos, se observou ansiedade e consequentemente, concentração. Outro ponto em comum foi a dificuldade de aplicação de conceitos em uma nova situação, competência prevista na Base Nacional Comum Curricular.

Em relação a Área 4 - Desafio do Fazendeiro, em termos de dificuldade de execução, essa atividade foi considerada a mais fácil, porém era a que mais trabalhava conceitos de algoritmos no dia a dia, bem como, o raciocínio lógico e habilidades do PC como a simulação e construção de algoritmos. Esses pontos foram abordados constantemente durante todo o decorrer do projeto, fazendo com que a atividade tivesse $100 \%$ de êxito conforme o exposto na Tabela 6. 
VII Congresso Brasileiro de Informática na Educação (CBIE 2018)

Anais dos Workshops do VII Congresso Brasileiro de Informática na Educação (WCBIE 2018)

Tabela 6. Resultados Área 4

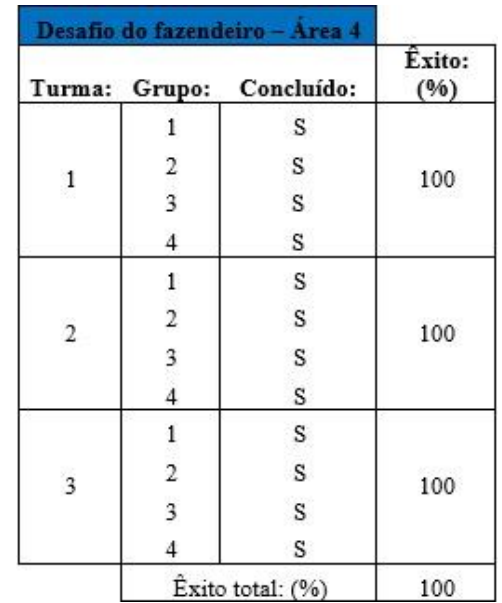

Por fim, buscando avaliar o desempenho das turmas de maneira geral, foi elaborada a Tabela 7 contendo os dados da pontuação final de cada grupo.

Tabela 7. Resultados Finais

\begin{tabular}{|c|c|cccc|c|c|c|}
\hline \multicolumn{10}{|c|}{ Turma } & \multirow{2}{*}{ Grupo } & \multicolumn{7}{|c|}{ Area } & Penalidades & Total & $\begin{array}{c}\text { Média da } \\
\text { turma }\end{array}$ \\
\cline { 2 - 6 } & & 1 & 2 & 3 & 4 & & \\
\hline \multirow{3}{*}{1} & 1 & 0 & 400 & 400 & 400 & 0 & 1200 & \\
& 2 & 400 & 400 & 0 & 400 & 0 & 1200 & 1000 \\
& 3 & 400 & 0 & 0 & 400 & 0 & 800 & \\
& 4 & 0 & 0 & 400 & 400 & 0 & 800 & \\
\hline \multirow{3}{*}{2} & 1 & 0 & 400 & 400 & 400 & 0 & 1200 & \\
& 2 & 0 & 400 & 400 & 400 & -50 & 1150 & \multirow{2}{*}{1187,5} \\
& 3 & 0 & 400 & 400 & 400 & 0 & 1200 & \\
& 4 & 0 & 400 & 400 & 400 & 0 & 1200 & \\
\hline \multirow{3}{*}{3} & 1 & 0 & 0 & 0 & 400 & 0 & 400 & \\
& 2 & 400 & 0 & 0 & 400 & 0 & 800 & 4 \\
& 3 & 0 & 0 & 0 & 400 & -50 & 350 & \\
& 4 & 0 & 0 & 0 & 400 & 0 & 400 & \\
\hline
\end{tabular}

De acordo com os dados da Tabela 7, se destaca que a média de desempenho da turma 2, que se deve ao melhor acompanhamento dos monitores, visto que já tinham a experiência da primeira turma e puderam melhorar sua atuação. A mesma observação não pode ser feita em relação a terceira turma que, por questão de horário, tinha diferentes monitores e mesmo buscando uma padronização na metodologia, pode ter ocasionado nos diferentes resultados.

\section{Considerações Finais}

O projeto Logicamente tem como finalidade motivar crianças e adolescentes a aprender programação, lógica e assuntos relacionados ao PC de maneira criativa, que são habilidades fundamentais para qualquer indivíduo.

Em relação ao lúdico proposto, no geral, foi observado que grupos que conseguiram trabalhar em equipe e desenvolver o raciocínio correto no tempo estipulado, acertaram os desafios. Os dados revelaram que houve certa 
VII Congresso Brasileiro de Informática na Educação (CBIE 2018)

Anais dos Workshops do VII Congresso Brasileiro de Informática na Educação (WCBIE 2018)

incompatibilidade de metodologia entre as turmas, afetando assim a pontuação final. Analisando por outra perspectiva, se pode afirmar que os objetivos foram alcançados, pois as habilidades do PC foram trabalhadas. Em paralelo, também houve o desenvolvimento das relações interpessoais e os estudantes se mostraram motivados durante a realização das atividades despertando positivamente a competitividade entre os grupos.

Como o Circuito trabalhou diferentes habilidades em cada jogo, ao final, se pode perceber os pontos fracos de cada turma, quais aspectos precisam ser revisados ou reforçados. Considerando o alto grau de dificuldade da expressão numérica, foi realizada a correção da mesma em sala de aula no encontro seguinte do projeto. Ao mesmo tempo, foi constatado que alguns estudantes que não se destacavam em sala de aula, tiveram um desempenho surpreendente. Da mesma forma, outros estudantes de destaque, puderam mostrar seus pontos fracos a ser trabalhados, como individualidade e dificuldade de ouvir sugestões. De maneira geral, a atividade arquitetada nos permitiu conhecer a significância de caráter social da atividade e não somente os aspectos conteudistas.

Por fim, de acordo com os resultados expostos na seção 3, o circuito foi considerado uma iniciativa interessante, que despertou curiosidade pelos temas abordados e favoreceu a compreensão dos assuntos relacionados reforçando os conteúdos trabalhados pelo projeto Logicamente.

\section{Referências Bibliográficas}

CSTA (2011, Julho). Operational Definition of Computational Thinking for $K-12$ Education. Retrieved

from:

https://c.ymcdn.com/sites/www.csteachers.org/resource/resmgr/

CompThinkingFlyer.pdf?hhSearchTerms $=\% 22$ computational+and + thinking $\% 22$.

Instituto Nacional de Estudos e Pesquisas Educacionais Anísio Teixeira INEP (2018).

Educação Básica, http://portal.inep.gov.br/web/guest/educacao-basica, março.

Sociedade Brasileira de Computação. (2017, Julho). Referenciais de Formação em Computação: Educação Básica. Retrieved from http://www.sbc.org.br/noticias/10slideshow-noticias/1996-referenciais-de-formacao-em-computacao-educacaobasical

Tangram 32 - Jogo Online (2017, março). Retrieved From https://rachacuca.com.br/jogos/tangram-32/

Wing, J. M. (2006). "Computational thinking”. Communications of the ACM, 49(3):3335. 